\title{
Quality of Life after Orthodontic Therapy from the Perspective of CS-OIDP
}

\author{
Ângela Cristina Pinto de Paiva Cunha1, Kenio Costa de Lima1, \\ Olga Benário Vieira Maranhão스, Ana Gláucia de Oliveira Macedo², \\ Anderson Farias da Cunha ${ }^{2}$, José Augusto Mendes Miguel $^{3}$ \\ ${ }^{1}$ Department of Dentistry, Federal University of Rio Grande do Norte, Natal, Brazil \\ ${ }^{2}$ Rehabilitation Hospital of Craniofacial Anomalies of São Paulo University (HRAC-USP), Bauru, Brazil \\ ${ }^{3}$ State University of Rio de Janeiro, Rio de Janeiro, Brazil \\ Email: angelapinto9@gmail.com, olgamaranhao@hotmail.com, anna_glaucia@hotmail.com, \\ afcnatal@hotmail.com
}

Received 20 October 2014; revised 25 November 2014; accepted 16 December 2014

Copyright (C) 2014 by authors and OALib.

This work is licensed under the Creative Commons Attribution International License (CC BY). http://creativecommons.org/licenses/by/4.0/

\section{(c) (i) Open Access}

\section{Abstract}

Objective: The aim of this study was to assess the impact of occlusal problems on quality of life in 288 patients who had undergone fixed orthodontic therapy, as well as to investigate the factors associated with this impact. Material and Methods: The orthodontic treatment needed by the IOTN index and the adequacy of treatment through the PAR index were evaluated in models. The impact on quality of life was assessed using the CS-OIDP index. For data analysis, we used the MannWhitney and Kruskal-Wallis test for a confidence level of $95 \%$. Results: The impact of malocclusion on quality of life was low, being present in $29.2 \%$ of cases. Performances of smiling, emotional state, and cleanliness of the mouth were the most affected. Factors related to the impact were the kind of service of the treatment performed, the need for orthodontic treatment, type of problem that motivated the treatment, and current age at the end of treatment. Conclusions: Despite the low impact, it was strengthened the hypothesis that patients undergoing orthodontic therapy had an improved quality of life.

\section{Keywords}

Quality of Life, Malocclusion, PAR, IOTN, CS-OIDP

Subject Areas: Dentistry, Epidemiology

\section{Introduction}

Malocclusions are considered a public health problem because of their high prevalence, possible prevention and

How to cite this paper: de Paiva Cunha, Â.C.P., de Lima, K.C., Maranhão, O.B.V., de Oliveira Macedo, A.G., da Cunha, A.F. and Miguel, J.A.M. (2014) Quality of Life after Orthodontic Therapy from the Perspective of CS-OIDP. Open Access Library Journal, 1: e1150. http://dx.doi.org/10.4236/oalib.1101150 
treatment, as well as causing social impact by interfering in the quality of life of individuals. The dentofacial disharmony may negatively influence people's lives in relation to psychosocial factors [1]. The demand for direct orthodontic treatment is high, strengthening the hypothesis that these problems have significant social impact in a general context [2]. The main reason for the demand of orthodontic treatment has been the improvement in the dentofacial appearance, more than the need for proper correction [3].

More recently, the incorporation of subjective measures to assess the impact of occlusal problems in people's lives has been observed, thus the need perceived by individuals [4]. This new approach by Chaves (1986) meets the above, which refers to the search for a criteria of related treatment needed from the point of view of the adjustment of the individual in society [5].

The literature theoretically suggests that orthodontic treatment promotes many psychosocial benefits [5]-[8]. However, the assessment of changes of pre or post orthodontic and/or orthosurgical treatment is based on traditional clinical measures, but it is the perception of the individual which is the central link of any need and satisfaction of treatment [9] [10].

In recent decades, several instruments for the assessment of quality of life related to oral health life were developed. The oral impact on daily performance (OIDP) is a type of specific OHRQoL measure of the group (Oral Health-Related Quality of Life), which seeks to relate these oral problems to quality of life [10]-[12]. When used to evaluate an oral health problem, it can be referred to as a specific condition of oral impact on daily performance (CS-OIDP) modified by Locker in 1988 for its use in Odontology [10]. Another positive factor of the CS-OIDP is that it also assesses the intensity and/or extent of the impact [13] [14].

Based on this, the study aimed to assess the impact of occlusal problems on quality of life in adults who have undergone fixed orthodontic therapy, as well as to investigate the factors associated with this impact, taking into consideration reports of a negative impact on quality of life of individuals.

\section{Materials and Methods}

This study is characterized as an exploratory, observational, and cross-sectional study which evaluated 288 adults undergoing fixed orthodontic therapy, aged between 18 - 70 years, and treated both in public and private facilities in Natal, RN, Brazil. The study population was selected from graduate courses offered by the Academy of Dentistry of Rio Grande do Norte and the Brazilian Dental Association of Rio Grande do Norte-ABO/RN, and private offices that make up the cases were treated in private hospitals. The present study was approved by the Ethics Committee (CEP) of the Federal University of Rio Grande do Norte (Brazil).

Prior to analysis of study models, a calibration of the examiners was held in order to ensure uniformity of interpretation, understanding, and application of the occlusal index: IOTN (Index of Treatment Need) which is used to classify the severity of orthodontic treated cases, and PAR (Peer Assessment Rating) used to balance the level of orthodontic treated cases in different institutions of the study. For this purpose, the first step consisted of the study of criteria for data collection from study models, through discussion of articles and explanation of each occlusal index. The second phase consisted of a pilot study whose objective was to provide examiners with the establishment of criteria for analysis and measurement of occlusal indices; which was made using 30 selected models with several cases of malocclusion.

After this phase, there was an inter-calibration. This calibration was also performed in this pilot study assessing 30 study models. Thus, an acceptable standard of kappa value equal to or greater than 0.80 was considered in each of the indices evaluated. Therefore, the lowest kappa value obtained in this step was greater than 0.86 for all variables studied.

The independent variables were divided into two groups: socio-economic demographic variables (type of service, age, gender, current age, and age at end of treatment) and the independent orthodontic variables (satisfactory use of retainer, time of use of retainer, undergoing speech therapy, main problems reported, IOTN-DHC, IOTN-AC, initial PAR, final PAR, difference between initial and final PAR). IOTN-DHC was used as a component of dental health, whereas the IOTN-AC was used as an aestetic component.

The initial categorization of the need for orthodontic treatment was obtained through the IOTN (Index of Treatment Need) index and quality of 20 cases treated in private and public networks were investigated with the PAR index, through the improvement rate of post-orthodontic therapy [15].

To collect data related to quality of life, the CS-OIDP (Condition-Specific Forms of the Oral Impacts on Daily Performances) index was used, which evaluated the specific condition of the oral impact on daily per- 
formance and analysed if the correction of maloclusion has impacted or not in the quality of life of the patients. This impact was collected through the analysis of eight daily performances, these being: eating, speaking, cleaning the mouth, relaxing, smiling, studying, emotional status, and social contact. Performances as frequency and severity of the impact range was not considered in this study. If no impact was reported, the score of zero was assigned. The impact score for each of the eight performances was estimated by multiplying the score of the corresponding frequency and their respective severity. The total score for the OIDP attributed to malocclusion was the sum of the scores of the eight performances (in a range from 0 to 72), multiplied by 100 and divided by 72.

Initially, a descriptive analysis of all variables was performed at the expense of measures of absolute and relative frequency and statistical indices that summarize the data. For data analysis, aiming to relate factors associated with the CS-OIDP, we used the Mann-Whitney and Kruskal-Wallis test for a confidence level of 95\%.

\section{Results}

The characterization results of the sample is according to the Table 1.

The impact of malocclusion on quality of life was low with an average of 2.56 and a standard deviation of 6.55, but was still present in $29.2 \%$ of patients, despite orthodontic treatment being performed. In this study, any higher minimum impact than zero was considered. The performances of smiling, emotional state, and cleanlyness of the mouth (10.4\%, $10.4 \%$ and $10.1 \%$, respectively) were the most affected (Figure 1).

Making an association between the type of service and the CS-OIDP index, patients in the private health sector reported more impact than undergoing treatment in public services. Another aspect observed in this study was that the older the patient was, the more likely the individual revealed an impact on quality of life, as individuals under age 21 years, both in the current age and the age after completion of orthodontic therapy had smaller values of CS-OIDP (Table 2).

Independent variables related to orthodontic therapy, as the main problems that caused the patient to seek orthodontic therapy, conducting additional speech therapy, whether or not retainer used satisfactorily according to

Table 1. Descriptive analysis of the independent variables.

\begin{tabular}{|c|c|c|c|}
\hline \multicolumn{2}{|c|}{ VARIABLES } & \multirow{2}{*}{$\begin{array}{c}\mathbf{N} \\
136\end{array}$} & \multirow{2}{*}{\begin{tabular}{|c|}
$\%$ \\
47.2
\end{tabular}} \\
\hline \multirow{2}{*}{ Services } & Public & & \\
\hline & Private & 152 & 52.8 \\
\hline \multirow{2}{*}{ Gender } & Female & 166 & 57.6 \\
\hline & Male & 122 & 42.4 \\
\hline \multirow{3}{*}{ Level of Education } & Average & 75 & 26.0 \\
\hline & College Not Completed & 40 & 13.9 \\
\hline & Graduated College & 173 & 60.1 \\
\hline \multirow{4}{*}{ Main Problems } & Bad tooth positioning & 152 & 52.8 \\
\hline & Space between teeth & 93 & 32.3 \\
\hline & Deformity of the mouth and face & 22 & 7.6 \\
\hline & Others & 21 & 7.3 \\
\hline \multirow{2}{*}{ Speech Therapy } & Yes & 89 & 30.9 \\
\hline & No & 199 & 69.1 \\
\hline \multirow{2}{*}{ Satisfactory Use of Retainer } & Yes & 256 & 88.9 \\
\hline & No & 32 & 11.1 \\
\hline \multicolumn{2}{|c|}{ VARIABLES } & MEAN & STANDARDDEVIATION \\
\hline Current Age & & 31.50 & 10.41 \\
\hline Final Age Post-Treatment & & 28.83 & 10.94 \\
\hline Time to Remove the Unit/Months & & 44.22 & 40.92 \\
\hline
\end{tabular}




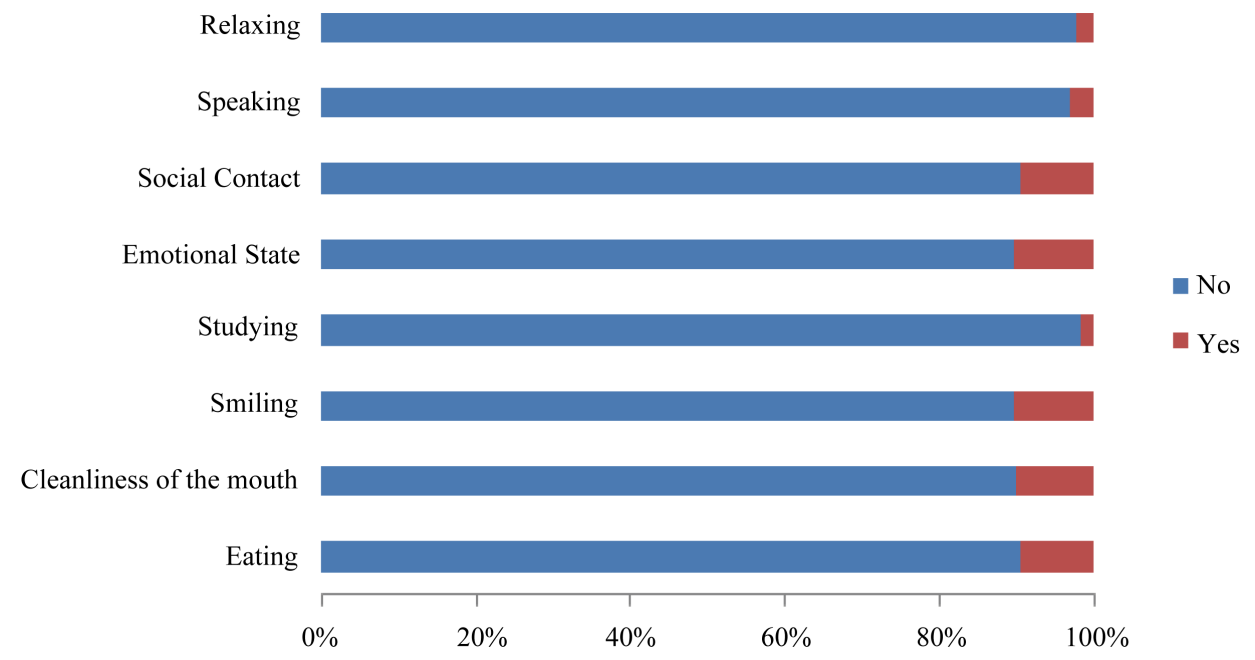

Figure 1. Variables that most impacted after orthodontic treatment.

Table 2. Mid table $\mathrm{Q}_{25}$ - $\mathrm{Q}_{75}$ CS-OIDP regarding socio-economic demographic independent variables.

\begin{tabular}{|c|c|c|c|c|c|}
\hline \multicolumn{2}{|c|}{ VARIABLES } & $\mathbf{N}$ & MEDIAN & $\mathbf{Q}_{25}-\mathbf{Q}_{75}$ & VALUE OF $p^{*}$ \\
\hline \multirow{2}{*}{ Type of service } & Public & 136 & 0 & $0.00-0.00$ & \multirow{2}{*}{$<0.001$} \\
\hline & Private & 152 & 0 & $0.00-2.78$ & \\
\hline \multirow{2}{*}{ Gender } & Female & 166 & 0 & $0.00-1.39$ & \multirow{2}{*}{0.431} \\
\hline & Male & 122 & 0 & $0.00-1.39$ & \\
\hline \multirow{3}{*}{ Education } & High School $^{\mathrm{a}}$ & 75 & 0 & $0.00-0.00$ & \multirow{3}{*}{0.105} \\
\hline & Some College $\mathrm{e}^{\mathrm{a}}$ & 40 & 0 & $0.00-0.00$ & \\
\hline & Graduated College $^{\mathrm{a}}$ & 173 & 0 & $0.00-2.08$ & \\
\hline \multirow{3}{*}{ Current age } & Up to 21years ${ }^{\mathrm{a}}$ & 105 & 0 & $0.00-0.00$ & \multirow{3}{*}{$<0.001$} \\
\hline & 22 to 33 years $^{\mathrm{b}}$ & 91 & 0 & $0.00-0.00$ & \\
\hline & Over 33 years $^{\mathrm{b}}$ & 92 & 0 & $0.00-4.17$ & \\
\hline \multirow{3}{*}{$\begin{array}{c}\text { Age after orthodontic } \\
\text { treatment }\end{array}$} & Up to 25 years $^{\text {a }}$ & 104 & 0 & $0.00-0.00$ & \multirow{3}{*}{0.010} \\
\hline & 26 to 35 years $^{\mathrm{b}}$ & 92 & 0 & $0.00-1.39$ & \\
\hline & Over 35 years $^{\mathrm{b}}$ & 92 & 0 & $0.00-3.82$ & \\
\hline
\end{tabular}

"p value overall, ${ }^{\text {a }}$, ${ }^{\text {: }}$ post-tests with Mann-Whitney and Bonferroni correction.

self-patient assessment and time of use of this retainer not significantly associated with oral impacts on daily performances. Regarding the need for early orthodontic treatment, there was only a significant association with IOTN-DHC, thus not having IOTN-AC (Table 3).

Therefore, the factors related to the impact were the kind of service in which the treatment was performed, the need for orthodontic treatment, the type of problem that motivated treatment, and current age and age at the end of treatment.

\section{Discussion}

When evaluating the impact of malocclusion on quality of life, the level of evidence of articles available in the literature, according to a systematic review, is relatively low as most studies in this area are of the cross-sectional type [16]. However, there is a consensus that orthodontic treatments with or without orthognathic surgery are the ones that require the use of socio-dental indicators among all dental specialties, for practically generating a large psychosocial influence on patients during all of the treatment time and also having the characteristic that, in some cases, aim for small or large facial changes [9] [16]-[18]. 
Table 3. Table median $\mathrm{Q}_{25}-\mathrm{Q}_{75}$ CS-OIDP in relation to orthodontic independent variables.

\begin{tabular}{|c|c|c|c|c|c|}
\hline \multicolumn{2}{|c|}{ VARIABLES } & \multirow{2}{*}{$\begin{array}{l}\mathbf{N} \\
89\end{array}$} & \multirow{2}{*}{$\begin{array}{c}\text { MEDIAN } \\
0\end{array}$} & \multirow{2}{*}{$\begin{array}{c}\mathbf{Q}_{25}-\mathbf{Q}_{75} \\
0.00-1.39\end{array}$} & \multirow{3}{*}{$\begin{array}{c}\text { VALUE OF } \mathbf{p}^{*} \\
0.835\end{array}$} \\
\hline & Yes & & & & \\
\hline Speech Therapy & No & 199 & 0 & $0.00-1.39$ & \\
\hline \multirow[b]{2}{*}{ Satisfactory use of retainer } & Yes & 256 & 0 & $0.00-1.39$ & \multirow[b]{2}{*}{0.212} \\
\hline & No & 32 & 0 & 0 & \\
\hline \multirow[b]{2}{*}{ Duration of retainer use } & Up to 12 months & 213 & 0 & $0.00-1.39$ & \multirow[b]{2}{*}{0.782} \\
\hline & Over 12 months & 53 & 0 & $0.00-1.39$ & \\
\hline \multirow{4}{*}{ Main Problem } & Badly positioned teeth ${ }^{\mathrm{a}}$ & 152 & 0 & $0.00-2.78$ & \multirow[t]{4}{*}{0.017} \\
\hline & Space between teeth ${ }^{\mathrm{a}}$ & 93 & 0 & 0 & \\
\hline & Mouth or Face Deformity ${ }^{\mathrm{b}}$ & 22 & 0.69 & $0.00-12.84$ & \\
\hline & Others $^{\mathrm{a}}$ & 21 & 0 & $0.00-1.39$ & \\
\hline \multirow{2}{*}{ IOTN-DHC } & $\begin{array}{l}\text { Without or less than needed } \\
\text { treatment }\end{array}$ & 109 & 0 & 0 & \multirow{2}{*}{0.019} \\
\hline & $\begin{array}{l}\text { Moderate or more than needed } \\
\text { treatment }\end{array}$ & 179 & 0 & $0.00-2.78$ & \\
\hline \multirow{2}{*}{ IOTN-AC } & $\begin{array}{l}\text { Without or less than needed } \\
\text { treatment }\end{array}$ & 160 & 0 & $0.00-1.39$ & \multirow{2}{*}{0.838} \\
\hline & $\begin{array}{l}\text { Moderate or more than needed } \\
\text { treatment }\end{array}$ & 128 & 0 & $0.00-1.39$ & \\
\hline \multirow{2}{*}{ Initial PAR } & Up to 14 & 154 & 0 & $0.00-1.39$ & \multirow{2}{*}{0.668} \\
\hline & Over 14 & 134 & 0 & $0.00-1.39$ & \\
\hline \multirow{2}{*}{ Final PAR } & 0 & 230 & 0 & $0.00-1.39$ & \multirow{2}{*}{0.863} \\
\hline & Over 0 & 58 & 0 & $0.00-1.74$ & \\
\hline \multirow{2}{*}{$\begin{array}{c}\text { Difference } \\
\text { Initial PAR-Final PAR }\end{array}$} & Up to 13 & 153 & 0 & $0.00-1.39$ & \multirow{2}{*}{0.314} \\
\hline & $>13$ & 132 & 0 & $0.00-1.43$ & \\
\hline
\end{tabular}

${ }^{*}$ p value overall, ${ }^{\text {a }}$ b $:$ post-tests with Mann-Whitney and Bonferroni correction.

According to Sheiham (2000), the use of socio-dental indicators, offers important advantages for the planning and provision of dental services, and the main thing is the shift in emphasis from purely biological aspects to psychological and social aspects [19].

Thus, taking into account that untreated malocclusion reflects this physical, psychological, and social impact on daily life, patients who possessed moderate or high need for orthodontic treatment at the beginning of orthodontic therapy ( $p=0.019$ ), observed through the IOTN-DHC, also showed to have the greater impact on quality of life than those with little need for treatment. This corroborates studies which found that those patients who rated themselves as aesthetically bad were far more likely to have a negative effect on quality of life than those who were satisfied with their aesthetics [20] [21]. These same findings were also reported by studies evaluating the association of severe need for orthodontic treatment through the IOTN, with quality of life [21]-[24].

In evaluating current research, the impact of socio-dental malocclusions in children or adolescents, only some evaluate the prevalence of this impact [22] [24]. In the present study, the sample consisted of individuals aged 18 - 70 years who underwent corrective orthodontic therapy in public and private services. The post-orthodontic therapy impact was low, averaging 2.56, assuming that the score of zero indicates no impact, but still present in 29.2\% of patients. The prevalence of this impact, in the study by Soares and Lima (2011) was the highest, 55.3\%, and also when compared to other studies, Barnábe et al., 2007; Gherunpong et al., 2006; Marques et al., 2005; Peres et al., 2009, who found a lower prevalence, 21.2\% 24.6\%, 20.3\% and 27\%, and 36.4\%, respectively [25]-[29]. However, it should be emphasized that some of these studies conducted research on patients under the age of 18 and without previous orthodontic treatment [25] [27] [28]. In this study, the fact that the impact was 
low but this post-orthodontic treatment can be justified because it was punctuated by adults older than 33 years ( $p<0.001$ ), and especially those submitted to private therapy $(\mathrm{p}<0.001)$, assuming that this group are more critical of their appearance in relation to adolescents or patients treated in public services and therefore stressed greater impact on quality of life even without severe occlusal alteration present. Shafiulla et al. (2009) emphasized that from the stage of adolescence, the concern with dental appearance increased [30].

There were no significant differences between genders nor with regard to degree of education among them, and also there was no significant influence between them or the results found by CS-OIDP. Therefore, not withstanding the current study, there has been a gender balance and in some studies it was observed that females report having a greater impact of their malocclusion on quality of life, which affirms to women being much more critical of their self-image and its impact on aesthetics [22] [23] [31] [32].

When individually evaluating the performance that affects the quality of life, Smiling (10.4\%) and emotional state (10.4\%) were the highest scores, but little difference with clean mouth (10.1\%), reinforcing the idea of the association of the impact factor on aesthetics and corroborating studies have also reported the smile as the performance that is the most bothersome [32] [33].

Regarding orthodontic independent variables, it was observed that individuals who scored the bad tooth position as the main factor that led to the search for orthodontic therapy, but the factor that showed a significant comparison was deformity of the mouth and face $(\mathrm{p}=0.017)$, which also indicates the greater importance of aesthetic factor.

Findings in this regard are supported by the study of Bernabé et al. (2007), which found that changes with emphasis on the anterior segment had a major negative impact on quality of life [26]. Based on this hypothesis, several studies have reported that dentofacial aesthetics play an important role in both social interaction as well as the psychosocial well-being, where the dental appearance has greater importance than when it is a measured aspect of the functional amendment itself [21] [28] [31]. Because of these findings, and the report of Shaffiula et al. (2009), it is justified to argue that the quest for orthodontic treatment is influenced primarily by the desire to look attractive in search of improved self-esteem [30].

Given these analyzes, it is valuable to realize that dental aesthetics has great influence on the demand for dental services, as the cosmetic change interferes with both social and psychological aspects, especially in the age range studied, where the adult is inserted in the social environment in a more active way.

Following this context that involves adults, we sought to further evaluate the quality of the treated cases (PAR), and whether or not the speech therapy, as well as the proper use of a retainer after orthodontic treatment would influence the results, but no significant relationship was found in this study.

Therefore, it is necessary that further studies are conducted, especially on adults, so that they can increasingly scientifically support the impact of malocclusion on quality of life of adults. Regardless of the social class to which the individual belongs, they also have the right to improve their oral health, to improve their self-esteem, and their psychosocial aspect, which also justifies the expansion of dental care, promoting improvement of oral health of the entire population of an egalitarian and universal society.

\section{Conclusion}

It was observed that for the patient to not experience any impact on quality of life, there would have to be no complaints present in the 9 evaluated performances, according to the analysis of the CS-OIDP, and the low impact presented strengthens the hypothesis that patients undergoing orthodontic therapy have an improved quality of life.

\section{References}

[1] Andrade, E.O., Gouveia, V.V., D’Ávila, R.L., et al. (2012) Index of Health Development: Conceptualization and Reflections on Its Need. Revista da Associação Médica Brasileira, 4, 413-421. http://dx.doi.org/10.1016/S0104-4230(12)70222-1

[2] Proffit, W.R., Fields, H.W. and Moray, L.J. (1998) Prevalence of Malocclusion and Orthodontic Treatment Need in the United States: Estimates from the NHANES III Survey. International Journal of Adult Orthodontics and Orthognathic Surgery, 2, 97-106.

[3] British Dental Association. Memorandum on Orthodontic Services (1954) British Dental Association.

[4] Manjith, C.M., Karnam, S.K., Manglam, S., Praveen, M.N. and Mathur, A. (2012) Oral Health-Related Quality of Life 
(OHQoL) among Adolescents Seeking Orthodontic Treatment. Journal of Contemporary Dental Practice, 3, $294-298$. http://dx.doi.org/10.5005/jp-journals-10024-1140

[5] Albino, J., Cunat, J.J., Fox, R.N., Lewis, E.A., Slakter, M.J. and Tedesco, L.A. (1981) Variables Discriminating Individuals Who Seek Orthodontic Treatment. Journal of Dental Research, 9, 1661-1667. http://dx.doi.org/10.1177/00220345810600090501

[6] Birkeland, K., Boe, O. and Wisth, P. (1996) Orthodontic Concern among 11-Year-Old Children and Their Parents Compared with Orthodontic Treatment Need Assessed by IOTN. American Journal of Orthodontics and Dentofacial Orthopedics, 2, 197-205. http://dx.doi.org/10.1016/S0889-5406(96)70109-9

[7] Kyiak, H.A. and Reichmuth, M. (2002) Body Image Issues in Dental Medicine. In: Cash, T.F. and Pruzinsky, T., Eds., Body Image: A Handbook of Theory, Research and Clinical Practice, Guilford Publications, New York, 342-350.

[8] Klages, U., Bruckner, A. and Zentner, A. (2004) Dental Aesthetics, Self-Awareness, and Oral Health-Related Quality of Life in Young Adults. European Journal of Orthodontics, 26, 507-514. http://dx.doi.org/10.1093/ejo/26.5.507

[9] Oliveira, C.M. and Sheiham, A. (2004) Orthodontic Treatment and Its Impact in Oral Health-Related Quality of Life in Brazilian Adolescents. Journal of Orthodontics, 31, 20-27. http://dx.doi.org/10.1179/146531204225011364

[10] Bowling, A. (2005) Measuring Health: A Review of Quality of Life Measurement Scales. 3rd Edition, Open University Press, England.

[11] Locker, D. (1988) Measuring Oral Health: A Conceptual Framework. Community Dental Health, 5, 3-18.

[12] Locker, D. (2004) Oral Health and Quality of Life. Oral Health \& Preventive Dentistry, 2, 247-253.

[13] Daniels, C. and Richmond, S. (2000) The Development of the Index of Complexity, Outcome and Need (ICON). British Journal of Orthodontics, 27, 149-162. http://dx.doi.org/10.1093/ortho/27.2.149

[14] DeGuzman, L., Bahiraei, D., Vig, K.W., Weyant, R.J. and O’Brien, K. (1995) The Validation of the Peer Assessment Rating Index for Malocclusion Severity and Treatment Difficulty. American Journal of Orthodontics and Dentofacial Orthopedics, 107, 172-176. http://dx.doi.org/10.1016/S0889-5406(95)70133-8

[15] Richmond, S., Shaw, W.C., Roberts, C.T. and Andrews, M. (1992) The PAR Index (Peer Assessment Rating): Methods to Determine Outcome of Orthodontic Treatment in Terms of Improvement and Standards. The European Journal of Orthodontics, 14, 180-187. http://dx.doi.org/10.1093/ejo/14.3.180

[16] Liu, Z., Mcgrath, C. and Hägg, U. (2009) The Impact of Malocclusion/Orthodontic Treatment Need on the Quality of Life: A Systematic Review. Angle Orthodontist, 79, 585-591.

[17] De Paula Júnior, D.F., Santos, N.C., Da Silva, E.T., Nunes, M.F. and Leles, C.R. (2009) Psychosocial Impact of Dental Esthetics on Quality of Life in Adolescents. Angle Orthodontist, 79, 1188-1193. http://dx.doi.org/10.2319/082608-452R.1

[18] Feu, D., Oliveira, B.H., Sales, H.X. and Miguel, J.A.M. (2010) Oral Health-Related Quality of Life and Orthodontic Treatment Seeking. American Journal of Orthodontics and Dentofacial Orthopedics, 138, 152-159. http://dx.doi.org/10.1016/j.ajodo.2008.09.033

[19] Sheiham, A. (2000) A determinação da necessidade de tratamento odontológico: Uma abordagem social. In: Pinto, V.G., Ed., Saúde bucal coletiva, Santos.

[20] Feu, D., Oliveira, B.H., Sales, H.X. and Miguel, J.A.M. (2008) Más-Oclusões e seu impacto na qualidade de vida de adolescentes que buscam tratamento ortodôntico. Ortodontia SPO, 41, 355-365.

[21] Feu, D., Oliveira, B.H., Sales, H.X. and Miguel, J.A.M. (2010) Oral Health-Quality of Life and Orthodontic Treatment Seeking. American Journal of Orthodontics and Dentofacial Orthopedics, 138, 152-159. http://dx.doi.org/10.1016/j.ajodo.2008.09.033

[22] Bernabé, E., Tsakos, G., Oliveira, C.M. and Sheiham, A. (2008) Impacts on Daily Performances Attributed to Malocclusions Using the Condition-Specific Feature of the Oral Impacts on Daily Performances Index. Angle Orthodontist, 78, 241-247. http://dx.doi.org/10.2319/030307-111.1

[23] Bernabé, E., Krisdapong, S., Sheiham, A. and Tsakos, G. (2009) Comparison of the Discriminative Ability of the Generic and Condition-Specific Forms on the Child-OIDP Index: A Study on Children with Different Types of Normative Dental Treatment Needs. Community Dentistry and Oral Epidemiology, 37, 155-162. http://dx.doi.org/10.1111/j.1600-0528.2008.00456.x

[24] Haag, U., Zhang, M. and McGrath, C. (2007) Who Knows More about the Impact of Malocclusion on Children’s Quality of Life, Mothers or Fathers? The European Journal of Orthodontics, 29, 180-185. http://dx.doi.org/10.1093/ejo/cj1058

[25] Soares, A. and Lima, K.C. (2011) Impacto sócio-dentário das oclusopatias e suas respectivas necessidades de tratamento na qualidade de vida de adolescentes. Dissertation, Universidade Federal do Rio Grande do Norte, Natal.

[26] Bernabé, E., de Oliveira, C.M. and Sheiham, A. (2007) Condition-Specific Sociodental Impacts Attributed to Different 
Anterior Occlusal Traits in Brazilian Adolescents. European Journal of Oral Sciences, 115, 473-478. http://dx.doi.org/10.1111/j.1600-0722.2007.00486.x

[27] Gherunpong, S., Tsakos, G. and Sheiham, A. (2006) A Socio-Dental Approach to Assessing Children’s Orthodontic Need. The European Journal of Orthodontics, 28, 393-399. http://dx.doi.org/10.1093/ejo/cji114

[28] Marques, L.S., Barbosa, C.C., Ramos-Jorge, M.L. and Paiva, S.M. (2005) Prevalência da maloclusão e necessidade de tratamento ortodôntico em escolares de 10 a 14 anos de idade em Belo Horizonte, Minas Gerais, Brasil: Enfoque Psicossocial. Cadernos de Saúde Pública, 21, 1099-1106. http://dx.doi.org/10.1590/S0102-311X2005000400012

[29] Peres, K.G., Peres, M.A., Araujo, C.L., Menezes, A.M. and Hallal, P.C. (2009) Social and Dental Status along the Life Course and Oral Health Impacts in Adolescents: A Population Based-Birth Cohort. Health and Quality of Life Outcomes, 7, 95. http://dx.doi.org/10.1186/1477-7525-7-95

[30] Shafiulla, M.D., Chandu, G.N. and Shivakumar, K.M. (2009) Prevalence of Malocclusion and Orthodontic Treatment Needs among Middle and High School Children of Davangere City, India by Using Dental Aesthetic Index. Journal of Indian Society of Pedodontics and Preventive Dentistry, 27, 211-218. http://dx.doi.org/10.4103/0970-4388.57655

[31] Leles, C.R., Paula Júnior, D.F., Santos, N.C.M., Silva, E.T. and Nunes, M.F. (2009) Psychosocial Impact of Dental Esthetics on Quality of Life in Adolescents. The Angle Orthodontist, 79, 1188-1193. http://dx.doi.org/10.2319/082608-452R.1

[32] Rusanen, J., Lahti, S., Tolvanen, M. and Pirttiniemi, P. (2010) Quality of Life in Patients Severe Malocclusion before Treatment. The European Journal of Orthodontics, 32, 43-48. http://dx.doi.org/10.1093/ejo/cjp065

[33] Bernabé, E. and Flores-Mir, C. (2006) Orthodontic Treatment Need in Peruvian Young Adults Evaluated through Dental Aesthetic Index. Angle Orthodontist, 76, 417-421. 